\title{
Películas y series televisivas en la enseñanza de la ética médica
}

\author{
Movies and TV series in teaching medical ethics
}

\section{Sr Editor:}

Los grandes avances de la ciencia médica desafían continuamente las competencias de los médicos para resolver dilemas éticos cada vez más diversos y complejos (en el ámbito clínico, científico, docente, gerencial, entre otros), por lo que urge que los médicos reconozcan a la Ética como parte importante del quehacer médico, y sepan cómo enfrentarse adecuadamente a los dilemas que se plantean en este ámbito (1).

Por ello, es importante volver la mirada hacia la enseñanza de la Ética en pregrado. Siendo necesario revisar y actualizar no solo en los tópicos que son atendidos en dicho curso, sino también en las metodologías utilizadas para su enseñanza.

De esta manera, se sabe que en varias facultades de medicina la metodología de enseñanza de este curso se basa en conferencias, lecturas y discusión de problemas éticos en pequeños grupos $(2,3)$, mientras que en Irán y Brasil, se ha reportado el uso del método Portafolio 2 (4), en el cual los estudiantes recogen casos o experiencias cotidianas que involucren un problema ético y los llevan a discusión junto a sus compañeros y profesores.

En un estudio realizado en Corea, en donde se implementó un curso para estudiantes de medicina de pre-grado para mejorar su entendimiento acerca del aspecto humanístico y social de la Medicina, revelo que las películas; entre otros métodos, ayudo a mejorar su entendimiento acerca de dichos temas, el cual se evidenció mediante un cuestionario bajo la puntuación de Likert, donde los estudiante mostraron una puntuación de 4 en relación a los objetivos de los temas tratados (5).

Universidades de Corea (5), Eslovenia (6) y Argentina (7), reportan el uso de métodos audiovisuales como complemento en la enseñanza tradicional de la Ética.

Las películas (o incluso series televisivas) pueden ser utilizadas en los cursos de ética para presentar de una manera impactante los problemas éticos a debatir, logrando que el estudiante se sienta inmerso en la trama y que inclusive "viva" el conflicto apasionadamente. Lo cual permite que los docentes tengan mayor facilidad para analizar, con una discusión grupal dirigida, los principales conflictos éticos que se reflejaron en la dramatización.

Con dicho fin, se puede seguir la siguiente metodología: para comenzar, el docente presenta brevemente el tema a discutir a los estudiantes. Posteriormente muestra el material audiovisual (en su totalidad o un extracto) haciendo hincapié en que el alumno deberá prestar atención a uno o varios conflictos éticos en particular. Una vez terminada la dramatización se inicia un debate por grupos moderado por el docente, quien facilitará las herramientas necesarias para favorecer el razonamiento crítico entre los estudiantes y desarrollar una discusión provechosa sobre el tema. Finalmente, se puede calificar el desempeño de los estudiantes en la sustentación del argumento planteado.

Esta iniciativa puede ser implementada con relativa facilidad en todas las facultades de medicina. Sin embargo, es necesario que los docentes conozcan el material que puede ser utilizado para dicho fin. Por ello, los autores de la presente comunicación han elaborado una lista de las películas y series televisivas (y los problemas éticos que pueden discutirse en cada una), en base a otras publicaciones y a sus propias experiencias como aficionados a discutir temas de ética (Tabla 1).

Actualmente existe una gran cantidad de material que se puede utilizar con este fin, y una lista exhaustiva 


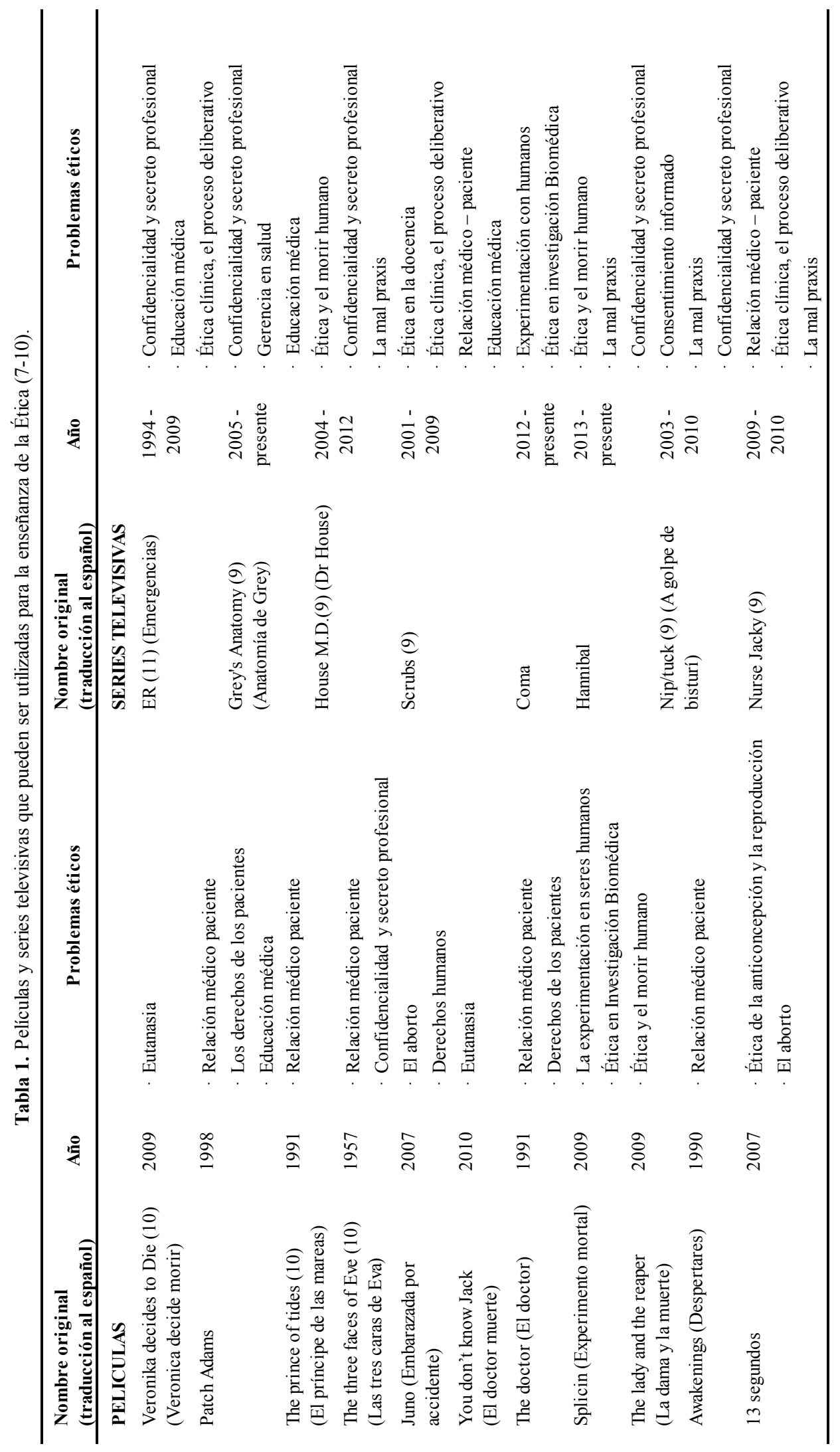


ocuparía cientos de páginas. Por ello, es necesario que los docentes experimenten con diversos materiales e identifiquen cuál es el mejor material para cada tema. También es necesaria la realización de estudios que comparen este con otros métodos que mejoren la discusión en los cursos de Ética. Todo con el fin de mejorar la preparación de los futuros médicos.

\section{Jorge García-Berrocal ${ }^{1,2, a}$, Alexander Zambrano- Huailla $^{1,2, a}$, Rommel Zambrano-Huailla ${ }^{1,2, a}$, Ernesto Zavala-Flores ${ }^{1,2, a}$, José Montes-Alvis ${ }^{1,2, a}$. \\ REFERENCIAS BIBLIOGRÁFICAS}

1. Goldie J. Review of ethical curricula in undergraduate medical education. Medical Education. 2000; 34(2):108-119.

2. Heidari A, Adeli S-H, Taziki S-A, et al. Teaching medical ethics: problem-based learning or small group discussion? J Med Ethics Hist Med. 2013; 6(1):1-6.

3. Mattick K, Bligh J. Teaching and assessing medical ethics: where are we now? J Med Ethics. .2006; 32(3):181-85.

4. Moreto G, Bariani DB, Pinheiro TR, Altisent R, González-Blasco P. Una nueva metodología docente en bioética: experiencias con la aplicación del portafolio a estudiantes de medicina en Brasil. Pers Bioét. 2008; 12(31):132-44.
5. Lee Y-M, Ahn D-S. Medical-themed film and literature course for premedical students. Med Teach. 2004; 26(6):534-9.

6. Klemenc-Ketis Z, Kersnik J. Using movies to teach professionalism to medical students. BMC Med Educ. 2011; 11(1):60.

7. Fariña JJM. A model for teaching bioethics and human rights through cinema and popular TV series: A methodological approach. Couns Psychol Q. 2009; 22(1):105-17.

8. González-Blasco P, Pinheiro T, Ulloa-Rodríguez M, Angulo-Calderón N. El cine en la formación ética del médico: un recurso pedagógico que facilita el aprendizaje. Pers. Bioet. 2009; 13(2): $114-27$

9. Padilla-Castillo G. Las series de televisión sobre médicos como ejemplo de enseñanza en nutrición y gastronomía. Revista Latina de Comunicación Social. 2012; 67:229-247.

10. Hernández P, García L. El uso del cine en la enseñanza de la psiquiatría. Ética \& Cine Journal. 2013; 3(3):55.

Recibido: 20/08/2014

Facultad de Medicina Humana, Universidad de San Martin de Porres, Lima, Perú.

2 Sociedad Científica de Estudiantes de Medicina de la Universidad de San Martin de Porres, Lima, Perú.

a Estudiante de Medicina Humana 